Article

\title{
Factors Affecting the Perceptions and Practices of Differentiated Curricula and Pedagogies for Gifted and Talented Students
}

\author{
Sandra N. Kaplan (D)
}

check for

updates

Citation: Kaplan, S.N. Factors Affecting the Perceptions and Practices of Differentiated Curricula and Pedagogies for Gifted and

Talented Students. Educ. Sci. 2022, 12, 41. https://doi.org/10.3390/ educsci12010041

Academic Editors: Dorothy Sisk and Jacobus G. Maree

Received: 18 October 2021

Accepted: 7 January 2022

Published: 11 January 2022

Publisher's Note: MDPI stays neutral with regard to jurisdictional claims in published maps and institutional affiliations.

Copyright: (C) 2022 by the author. Licensee MDPI, Basel, Switzerland. This article is an open access article distributed under the terms and conditions of the Creative Commons Attribution (CC BY) license (https:// creativecommons.org/licenses/by/ $4.0 /)$.
Rossier School of Education, University of Southern California, Los Angeles, CA 90007, USA; skaplan@usc.edu

\begin{abstract}
The definitions and implementation of differentiated curricula and instruction for gifted and talented students have been affected by a myriad of philosophical and institutional factors defined by educators, community members, and gifted and talented students. The ramifications of these factors affect the focus and subsequent objectives and outcomes of differentiated curricula and instruction for gifted and talented students. A set of questions regarding the structure and implications of differentiated curricula and instruction for gifted and talented students are presented. Concepts such as specificity versus generalization, transfer of training, and conflict of interests are discussed and exemplified theoretically, philosophically, and pragmatically to respond to these questions.
\end{abstract}

Keywords: differentiation; gifted; perceptions; curriculum; instruction

\section{Introduction}

Tyler identified four basic questions that needed to be addressed in his seminal work regarding principles of curriculum and instruction [1]:

1. What educational purposes should the school seek to attain?

2. What educational experiences should be provided that are likely to attain these purposes?

3. How can these educational experiences be effectively organized?

4. How can we determine whether these purposes are being attained?

"Challenging", "enrichment", "complexity", "individualized and personalized", "accelerated", "creative and critical thinking", and "process and product" are some of the common terms associated with the concept of differentiation. How and why these terms are included in or excluded from the definition and implementation of differentiated curricula for gifted and talented students will be addressed in relation to the implications of Tyler's questions, as well as questions derived from examining the philosophy and practices that promote or deter differentiation, which are as follows:

1. What are the primary and multiple purposes related to differentiating curricula and instruction for gifted and talented students?

2. How can the acceptance and implementation of differentiated curricula and instruction for gifted and talented students facilitate and compliment the basic or rudimentary curriculum defined for all students across subjects and grade levels?

3. How can teachers be educated to affectively and effectively develop the expertise needed to implement a differentiated curriculum?

4. How can the academic, personal, and social responses and outcomes of gifted and talented students as participants in differentiated curricular and instructional experiences be clearly understood and communicated to students, educators, and the community?

Some of the significant factors affecting differentiation for gifted and talented students are the political, social, cultural, and economic perspectives that consistently affect and shape general education. The consequences of these perspectives have far-reaching implications for both educators and gifted and talented students. These perspectives have the 
potential to define and redefine the dimensions that collectively impact and subsequently affect the policies, funding, anticipated goals or outcomes, and appropriate curricular and pedagogical practices responsive to gifted and talented students. However, the political, social, cultural, and economic factors that shape perceptions appear to affect verbiage more easily than they impact classroom curricular and pedagogical practices. The effect of these perceptions on changes in a district's curricular and pedagogical rhetoric are noted in the form of mission statements, policies, and the calendar of professional activities. It appears that the contemporary perspectives regarding the education of the gifted and talented are more readily accepted in print and professional discussions by educational institutions than as features impacting gifted and talented students in the classroom.

Grants and projects, research-based dissemination, journal articles, books, and general and topic-specific conferences affect the perceptions of educators about curricula and pedagogy that impact the gifted and talented. While the receptivity to the rhetoric appears to change perceptions, the same rhetoric is slower to affect changes in practice within the context of the classroom, or in services rendered to gifted and talented students across subjects and grade levels. The factors that possibly inhibit the translation from rhetoric to practice can be examined with regard to a set of conceptual factors such as specificity and generalizability, transfer of training, curricular and pedagogical equity, conflicts of interest, and the process of change.

\section{Specificity versus Generalizability}

The dissemination of a curriculum and pedagogy designed and researched to differentiate educational opportunities to meet the needs of gifted and talented students is often presented to teachers with an intensity of appropriateness for only gifted and talented students. The intensity of the curriculum's appropriateness for the gifted and talented can disassociate it from its potential application to other learners within the context of the same classroom. The perceived need to distinguish and separate the differentiated curriculum and pedagogy from all other students results in the hesitancy of teachers to fully translate the differentiated curriculum and pedagogy into practice in a heterogenous classroom. What about the other students' needs, interests, and abilities? One means to respond to a teacher's anxiety surrounding inclusion, rather than exclusion, regarding the implementation of the differentiated curriculum and pedagogy, is to discuss the "spill-over effect" [2], or the many and varied ways that the differentiated curriculum and pedagogy as a whole, or in segments, can be provided appropriately to students other than the gifted and talented within the classroom context. In addition, there is a need to amend the differentiated curriculum and pedagogy to meet the diversity of interests, needs, and abilities among gifted and talented students.

The decision to implement a differentiated curriculum and pedagogy, originally designed for gifted and talented students, to all students in a classroom as a means to provide the opportunity for every student to demonstrate their potential was examined in a research study conducted by the researcher in 2021 [3]. This method of applying a differentiated curriculum and pedagogy was used to uncover potential among students in the early years and was the primary objective of the study [3]. The project focused on distributing pedagogical tools and differentiated curricular lessons to teachers to give kindergarten to second grade students opportunities to show abilities that the core curriculum did not easily reveal [3]. The district's reliance on formal indicators of abilities such as achievement and intellectual scores were given more credibility to define a student's potential as gifted and talented than were the teacher's observations and acknowledgments of these abilities derived from the implementation of the project's differentiated curriculum and pedagogy. The lack of the translation of the teacher's curricular evidence of students' abilities into a formal indicator of these students as gifted and talented was a consequence of many issues. There are instances when evidence from a differentiated curriculum and pedagogy have not affected policies and procedures in time or over time. The development of policies that affect the acceptance and utilization of new and/or different curricular and pedagogical 
practices has been delayed due to the layers of decision-making and institutional situations that are often not considered during the development and implementation of a new and innovative differentiated curriculum and pedagogy. The implementation of a differentiated curriculum and pedagogy as a non-traditional measure in the early years has become a feature of conversation and is practiced by teachers who were involved in the project. To date, the impact of the differentiated curriculum and pedagogy from this project has not been realized beyond the teachers who participated in the project. This project, which has not yet been translated into curricular change beyond its original context, highlights a broader problem in which differentiated curricular and pedagogical practices are sometimes only continued within the districts, schools, and classrooms in which they were practiced and researched. The dissemination of a differentiated curriculum and pedagogy should not depend only on identified teachers who willingly implement these practices. Teachers need to be taught the nature of advocacy and the role of an advocate in order to disseminate these curricular and pedagogical practices. The role of the advocate should include the nature of collegial interactions, language patterns and debate methodologies, and presentation skills.

\section{Transfer of Training}

Importantly, the gap that results from the translation of a differentiated curriculum and pedagogy into classroom practices can be a result of the many and varied professional development opportunities that rival rather than support or reinforce each other. For example, a 2010 project that focused on the use of an array of different models of teaching to affect new forms of differentiated curricula and pedagogies was presented to teachers without commensurately demonstrating how these practices are aligned to other varied mandatory practices presented during professional development meetings [4]. In some cases, the professional development experiences compete or conflict with rather than complement each other. Teachers have either implemented the ideas gleaned from professional development meetings in isolation or have placed these ideas "on hold", so to speak, until the teacher can determine how and when to connect or associate them with their current curriculum and pedagogy. The challenge posed by the lack of transfer from training experience to classroom practice can be resolved for districts and schools by providing professional development experiences that demonstrate where, when, how, and why the newly acquired curricula and pedagogies relate to and complement each other. Joyce VanTassel-Baska and her colleagues' observations of 329 classrooms revealed that teachers employed differentiated strategies with some effectiveness and that more work is necessary for teacher preparation and administrative support to ensure teachers meet gifted students needs through differentiated instruction [5]. The analysis of the work of VanTassel-Baska and her colleagues emphasizes the continuous need for professional development for teachers in order to consistently provide opportunities to develop expertise and to master the integration of sophisticated and differentiated instructional strategies into the curriculum.

Data collected from the participating second, third, and fourth grade teachers reflect their conflicting beliefs regarding the integration of a differentiated curriculum and pedagogy into existing core curricular lessons (Table 1). School and district sanctions related to academic performance indicators were a significant factor in determining where and when in the core lesson differentiation could take place [4]. The lack of congruence between the intent of the differentiated curriculum and pedagogy and the teacher's implementation of the curriculum and pedagogy could be the result of differences between the goals of the curriculum and the teacher's philosophical beliefs. A teacher whose educational belief is aligned to a child-centered, inquiry-based philosophy might respond differently to the features of a differentiated curriculum and pedagogy than a teacher who is aligned to a didactic, group-oriented teaching frame of reference. A necessary variable to consider in the design, development, and implementation of a differentiated curriculum and pedagogy is the clarity of the definition and comprehension of its dominant philosophical objective. Perceptions of a differentiated curriculum and pedagogy are often the result of a mismatch 
between the philosophical approach of the curriculum and the philosophical belief of the educator.

Table 1. Teachers' Perceptions of When to Implement Differentiated Instruction.

\begin{tabular}{|c|c|c|c|c|c|c|c|}
\hline \multicolumn{8}{|c|}{ Teachers' Perceptions of When to Implement Differentiated Instruction } \\
\hline \multicolumn{2}{|c|}{ After a Basic Lesson } & \multicolumn{2}{|c|}{$\begin{array}{c}\text { Within a } \\
\text { Standards-Based } \\
\text { Lesson }\end{array}$} & \multicolumn{2}{|c|}{$\begin{array}{l}\text { Replacement to a } \\
\text { Core Lesson }\end{array}$} & \multicolumn{2}{|c|}{ Not Sure } \\
\hline $\mathrm{F}$ & $\%$ & $\mathrm{~F}$ & $\%$ & $\mathrm{~F}$ & $\%$ & $\mathrm{~F}$ & $\%$ \\
\hline 29 & $18 \%$ & 78 & $48 \%$ & 47 & $29 \%$ & 10 & $6 \%$ \\
\hline
\end{tabular}

\section{Conflicts of Interests}

Teachers are often confronted by curricular decisions that result in a conflict of interest. Such conflicts are derived from determining the features that should be included and emphasized to formulate a differentiated curriculum for gifted and talented students. Susan Johnsen and her colleagues identified theoretical and empirical concepts such as context, rate, preference or choice, and environment as essential ingredients to differentiate a curriculum [6]. Other curriculum developers and researchers have identified models to formulate decisions to differentiate a curriculum. Renzulli presents the Triad Model to differentiate a curriculum, which emphasizes the presentation of general exploratory enrichment activities (Type 1), the development of cognitive skills such as critical thinking and research skills (Type 11), and individualized or group investigations (Type 111) [7]. Carol Tomlinson and her colleagues describe a Parallel Curriculum model that defines four pathways to differentiation: Core Curriculum; Curriculum of Connections, or identifying how skills and concepts from curricular subjects or disciplines can be integrated; Curriculum of Practice, which emphasizes learning centered on a discipline; and Curriculum of Identify, which enables the development of personal interests and abilities [8]. Common to each of these differentiated curricular concepts or models is their relationship to the core or basic curriculum to some degree. The alignment of a differentiated curriculum and differentiated instruction to the core curriculum promotes their acceptance and ensures that differentiation is acknowledged as an essential feature in the education of gifted and talented students.

A substantive conflict of interest is the teachers' different perceptions of the nature of giftedness, their intellectual goals for the gifted and talented, and the many and varied attitudes about what constitutes a "differentiated" curriculum and pedagogy. The conceptions that the gifted and talented deserve more sophisticated curricular experiences or are more inclined to work independently have altered the intentionality and implementation of differentiated curricula and pedagogies designed for the gifted and talented. The discrepancies between the intended presentations of a differentiated curriculum versus the actual implementations of this same curriculum can illustrate the teachers' perceptions of the meaning of giftedness. These potential discrepancies were noted in a project that asked teachers to underline the elements of a differentiated curriculum that were responsive to their definition of a gifted and talented learner [4]. Teachers noted in the final summary of the five-year project that "conflicting expectations of curricula and time allocations" stated by the district or school affected their fidelity to the project's curriculum and pedagogical expectations for gifted and talented students [4]. In the same study, accountability and state standards were the primary determinants in the teachers' decisions to select and implement the traditional versus newly designed differentiated curriculum and pedagogy [4]. The teacher's implementation of a differentiated curriculum and pedagogy can affect students' attitudinal reference toward the curriculum. It was noted that students in the project had already developed a predisposition towards certain types of curricular and pedagogical experiences that they deemed more amenable to them. For example, second to fifth grade 
gifted and non-gifted students preferred a didactic curriculum and pedagogy for the teaching and learning of mathematics, while they preferred inquiry-based curricular methods for science and social studies [4]. The project substantiated the idea that students may be socialized to select certain types of pedagogy based on the frequency with which these are used by their teachers within the core or basic subject areas or disciplines.

Another conflict of interest that alters the perceptions of a differentiated curriculum and pedagogy derives from the teacher's understanding of the nature of giftedness, i.e., what gifted and talented students are and what they are not. An analogy regarding differentiated curricula and pedagogies is that these practices can be attributed to differing degrees of significance by different teachers implementing the same lesson or unit of study. For example, teachers exercise options to implement the same curriculum with different understandings of the importance of the features of the curriculum. Specifically, they place different emphases on sections or syntax of the same lesson. In the project, Models of Teaching, the researcher noted that teachers used different modes of presentation to teach the same lesson [4]. One teacher allocated a full period to the motivation feature of the lesson before introducing the demonstration section of the lesson. Another teacher in the same school and grade level introduced the motivation section of the lesson in $7 \mathrm{~min}$ and spent the remainder of the period focusing on the demonstration and application sections of the lesson [4]. Teachers' decisions regarding both their own and their students' relationships to the lesson comprise the decisions regarding the allocation of time and effort expended on the implementation of the curriculum. In addition, the choice of pedagogical emphasis was a differential feature among the teachers. Teachers' perceptions of themselves as teachers and of students as learners affect the integrity and impact of the differentiated curriculum and pedagogy. A teacher's perceptions and choices regarding the implementation of differentiated curricula and pedagogies have far-reaching effects on the teaching and learning process for gifted and talented students.

\section{Students' Perceptions}

An analysis of perceptions that students, both gifted and non-gifted, have about differentiated curricula and instruction is derived with respect to these basic areas of investigation: (1) differences in grade and subject area specification; (2) type and implementation of services that include either homogeneous or heterogeneous grouping that take place within or outside of the assigned or regular classroom; (3) implementation by the basic classroom teacher or specifically designated specialist such as a "teacher of the gifted", coach, or resource teacher. Underlying all these areas that can potentially shape students' responses to a differentiated curriculum and pedagogy are the following: the prevailing district or school's definition of giftedness; the needs, interests, and/or abilities that are defined as the traits or characteristics that each student uniquely manifests as a gifted or advanced learner; the instruments and systems of identification. This range of considerations needs to be acknowledged as educators seek to answer the question: "What are the multiple and contemporary factors that shape and define the perceptions of students about being identified as gifted?"

Students' perceptions concerning differentiated curricula and pedagogies are dependent on their understanding of the definition and the implications of the term "gifted" and the personal, social, and academic responsibilities that that are believed (by students, parents, and educators) to accompany the formal identification of being "gifted". This interpretation is often influenced and contradicted by a variety of factors: teacher and parent expectations, peer responses, and curriculum and instructional experiences that thwart rather than facilitate the students' opportunities to utilize and demonstrate their abilities. The perceived "loss of self" can be a consequence of misinterpretation or exaggerated expectations of the meaning of either "advanced" or "gifted" as a prerequisite to being a student or learner [9]. Being familiarized with the nature of scholarliness (habits and qualities of learning) versus scholarship (professional assessed practices) has abated some of the misconceptions regarding the nature of giftedness for students. Within the 
teaching and learning of the concepts related to "scholarliness" or "scholarly behaviors" are the meanings of these attributes: ponder, willingness to participate, goal and vision, risk taking, curiosity, sticking to the task, practice, thirst for knowledge.

As noted in Table 2, students gave the highest rankings to the scholarly behaviors "Ponder", "Curiosity", and "Thirst for Knowledge". The three highest-ranked traits are perceived to be dominant features within discussions related to the expected norms of intellectual behaviors in a classroom. Teachers have been known to comment on how important it is to deliberate or "ponder" and to be "curious" or "thirsty for knowledge" before and during a lesson. The following is an important question to consider when discussing the scholarly behaviors of gifted and talented students: To what degree do students define their own scholarly behaviors or adopt and demonstrate the behaviors that have been presented and subsequently praised by their teachers?

Table 2. Prioritization of Scholarly Behaviors by Gifted and Non-Gifted (Elementary).

\begin{tabular}{|c|c|c|}
\hline \multicolumn{3}{|c|}{ Prioritization of Scholarly Behaviors by Gifted and Non-Gifted (Elementary) } \\
\hline Ranking & Percentage & Scholarly Behavior \\
\hline 1 & $32 \%$ & Ponder \\
\hline $2 \mathrm{~A}$ & $20 \%$ & Curiosity \\
\hline $2 B$ & $20 \%$ & Thirst for Knowledge \\
\hline 3 & $12 \%$ & Risk Taking \\
\hline 4 & $11 \%$ & Perseverance \\
\hline 5 & $5 \%$ & Goal Setting \\
\hline
\end{tabular}

Note: From "Using Models of Teaching to Improve Student Achievement" [4].

Four different categories appear to identify the potential outcomes of differentiated curricular and pedagogical experiences for gifted and talented students: institutional, educational, social, and personal. Institutional outcomes appear to include the merits and notoriety that districts and schools derive from the accomplishments of advanced and gifted and talented students. Educational outcomes can be described as the goals that students and teachers meet to achieve the benchmarks set for either a grade level or subject area. In addition, as stated previously, teachers earn reputations for their prowess as instructors from the accomplishments of their gifted and advanced learners. Social outcomes, often expressed by family members as well as the gifted or advanced learner, are the benefits and recognition derived from the label "gifted" and the subsequent differentiated experiences afforded to the student. Personal outcomes are often associated with the affirmation of the definition of giftedness and the short- and long-term individual plans to attend higher education and pursue a selected profession.

One of the immediate and long-term outcomes of a differentiated curriculum and pedagogy for gifted and advanced learners should be "learning-to-learn." The learningto-learn concept can shift the outcomes of a differentiated curriculum and pedagogy from an emphasis on the content or "what" is to be learned to the "how" or methods of learning. This emphasis is predicated on the understanding that teaching students how to learn provides the foundation for learning and applying the pedagogical tools that enable students to learn independently within and outside the classroom and school contexts. Learning-to-learn includes the processes that enable the learner to understand that learning is dependent on the individual's ability to activate the procedural knowledge that directs the behaviors of learning. Gifted and non-gifted students were introduced to learning-to-learn strips that outlined the sequence of actions to learn a skill or content. The learning-to-learn strips were based on the didactic (direct instruction) and inquiry (advanced organizer and group investigation) models of teaching [4]. Table 3 illustrates the results of gifted and non-gifted students' perceptions of learning-to-learn skills and processes. Based on student's responses, inquiry and the ability to think and inquire 
independently were the most important learning-to-learn skills. This information supports more open-ended learning as a feature of a differentiated curriculum and pedagogy.

Table 3. Student's Perceptions of Learning-to-Learn Skills and Processes.

\begin{tabular}{|c|c|c|c|c|c|c|c|}
\hline \multicolumn{8}{|c|}{ Students' Perceptions of Learning-to-Learn Skills and Processes } \\
\hline $\begin{array}{c}\text { Observe or } \\
\text { study how } \\
\text { to do } \\
\text { something }\end{array}$ & $\begin{array}{l}\text { Ask my } \\
\text { own } \\
\text { questions }\end{array}$ & $\begin{array}{l}\text { Think } \\
\text { how to } \\
\text { apply it }\end{array}$ & $\begin{array}{l}\text { Meet an } \\
\text { unclear } \\
\text { idea and } \\
\text { think } \\
\text { what I } \\
\text { already } \\
\text { know }\end{array}$ & $\begin{array}{l}\text { Research } \\
\text { for infor- } \\
\text { mation }\end{array}$ & $\begin{array}{l}\text { Watch } \\
\text { somebody } \\
\text { else do it }\end{array}$ & $\begin{array}{l}\text { Practice } \\
\text { many } \\
\text { times }\end{array}$ & $\begin{array}{c}\text { Discuss } \\
\text { with } \\
\text { others }\end{array}$ \\
\hline $10 \%$ & $12 \%$ & $17 \%$ & $21 \%$ & $12 \%$ & $7 \%$ & $4 \%$ & $17 \%$ \\
\hline
\end{tabular}

\section{Defining Educational Activities That Impact and Change Teachers' Perceptions of Differentiated Curricula and Pedagogies}

Issues concerning why changes in teachers' perceptions regarding differentiated curricula and pedagogies have been discussed, investigated, reported, and implemented. However, suggestions are affected by multiple issues that either facilitate or hamper perceptions regarding differentiated curricula and pedagogies. A review of the issues that hamper the clarity of the perceptions of differentiated curricula and pedagogies reveals information that has the potential to shift, correct, and align teachers' perceptions with the intentionality of a differentiated curriculum and pedagogy's comprehension and implementation.

\subsection{Orientation}

A differentiated curriculum and pedagogy is most often introduced via some form of professional development that includes the rationale, content, and methods of differentiation. The usual centerpiece of an orientation to the topic of differentiation is a description of the negative consequences of not providing differentiation and the resulting academic, personal, and social ramifications. Differentiation of curricula and pedagogies needs to be introduced as a universal concept that is relevant to all students and should stress the need to recognize individual differences in all learners. The need to orient educators to the general as well as the specific nature of differentiation is fundamental to its acceptance at the outset of any orientation during professional development. Generalizing the intent of the term can generalize the implications of the process of differentiation.

The orientation to differentiation should also include exemplars of differentiated curricula and pedagogies in action. Whether the "in action" concept is presented virtually or in-person, viewing the ramifications of the act of differentiating a curriculum and pedagogy provides a reality to verbiage or visual cues provided by technology. It has been stated by some educators that demonstrations can create models that evoke "intimidation of replication"; however, if educators are aided in developing their skills of "observing", rather than assessing, while engaging in observation, the fear of imitation can be mitigated, if not eradicated. An additional aid to facilitating observational learning is to direct the observer's attention to specific features of the differentiated curriculum and pedagogy being taught to the gifted and talented students that they are observing. Learning from observation is an integral feature of acquiring skills that translate into a more knowledgeable performance by teachers. Observing art, observing dance, observing sports, and observing culinary chefs have contributed to becoming more aware of the skills that lead to proficiency. The results of observing teachers implementing a differentiated curriculum and pedagogy for gifted and talented students can facilitate educational expertise in these areas.

\subsection{Immersion}

The orientation or professional development experience should include immersion, or the modeling of multiple acts of a differentiated curriculum and pedagogy. The most frequent and often labeled the most difficult expectation from orientation or professional 
development appears to be the transfer of learning from orientation into classroom implementation. This transfer is often curtailed by the simple issue of time, or comprehending when to enact the differentiated curriculum and pedagogy within a teacher's own classroom schedule and curricular demands. The designation of time to differentiate for gifted and talented students should not be dependent solely on the teacher's schedule. Differentiation of a curriculum and pedagogy should be dependent on the developmental needs, interests, and abilities of the gifted and talented student and should include collaborative decision-making by the teacher and the gifted and talented student. The question that needs to be addressed is how to determine the appropriate time for the introduction and/or intersection of differentiation for gifted and talented students into the core curriculum. Is differentiation best introduced as the entry to the implementation of the basic curriculum, as a concurrent feature, or as the terminal assignment? The immersion of a differentiated curriculum and pedagogy for gifted and talented students also includes being able to justify the concept that differentiation is an integral feature of classroom practices and not an activity that is ancillary to the core or basic curriculum. Teachers' perceptions that differentiation is an addendum to, rather than an extension of, the basic or core curriculum has created misunderstandings of the value and significance of differentiation for gifted and talented students and the teacher who provides the experience to these students. The perceptions of a differentiated curriculum and pedagogy for the gifted and talented as a supplement rather than a rudimentary element of the curriculum will continue to allow differentiation to be misunderstood and easily and consistently subjected to the question of "why"?

\subsection{Contribution}

Teachers' positive perceptions towards a differentiated curriculum and pedagogy can be established when teachers are actively engaged in modifying and not merely implementing a differentiated curriculum and pedagogy. Most often teachers are led to believe that they are expected to replicate with fidelity the differentiated curriculum and pedagogy they have been introduced to in an orientation or professional development experience. Providing teachers with the understanding that they can employ changes to the implementation of a differentiated curriculum and pedagogy to meet the individual needs of their gifted and talented students is essential. This action could facilitate a different and more significant bond between teachers and the implementation of a differentiated curriculum and pedagogy within the classroom. Assisting teachers to develop the skills, resources, instructional strategies, and unique features that they perceive align with their students can provide them with the "ownership" and longevity essential to implementing a differentiated curriculum and pedagogy. Essential to the teachers' understanding of contributions is the knowledge of what features are amendable without affecting the integrity of the objectives of differentiation. Contributions to a differentiated curriculum and pedagogy are recognized as enhancing rather than distracting from the intent of differentiation and tend to encourage, not discourage, professional alignment to a differentiated curriculum and pedagogy for gifted and talented students.

\section{Summary}

Changes in the perceptions of differentiated curricula and pedagogies are inevitable, just as changes in the core or rudimentary curriculum are anticipated and accepted over time. Changes in differentiated curricula and pedagogies need to be developed and presented on a foundation inclusive of clear goals for the gifted and talented, the many and varied factors that shape teachers' receptivity to change, and the issues at stake in implementing a differentiated curriculum and pedagogy in tandem with other existing curricular and pedagogical demands.

Discussions and decisions about differentiated curricula and pedagogies are most often a consequence of the responses of key educational decision makers. While their perceptions of differentiated curricula and pedagogies for the gifted and talented affect teachers and 
gifted and talented students, it is interesting to note that gifted and talented students are omitted from the decision-making process. The concept of student involvement in curricular and instructional decisions could be a variable that may provide new insights into the perceptions and practices of differentiated curricula and pedagogies. Changing teachers' perceptions of differentiated curricula and pedagogies might be affected to a greater degree by their understanding of gifted and talented students' responses to differentiation. An analysis of gifted and talented students' perceptions of the intended and implemented differentiated curriculum and pedagogy designed to meet the very attributes that identify them as gifted and talented learners could be an integral feature of, or at least an adjunct to, developing the perceptions of teachers regarding the issues surrounding differentiated curricula and pedagogies.

Funding: This research received no external funding.

Institutional Review Board Statement: Not applicable.

Informed Consent Statement: Not applicable.

Data Availability Statement: Not applicable.

Conflicts of Interest: The author declares no conflict of interest.

\section{References}

1. Tyler, R. Basic Principles of Curriculum and Instruction; University of Chicago Press: Chicago, IL, USA; London, UK, 1949.

2. Kaplan, S.N. The Spill-Over Effect: An Advocacy Strategy. Gifted Child Today 2004, 27, 48-49. [CrossRef]

3. Kaplan, S.N. Project CHANGE (S206A140036) Final Performance Report. Department of Education, Jacob Javits Grant. 2021. Available online: https:/ / spark.uconn.edu/other-2014-javits-grant-awardees / (accessed on 24 September 2021).

4. Kaplan, S.N. Using Models of Teaching to Improve Student Achievement (S206A040072-07) Final Performance Report. Department of Education, Jacob Javits Grant. 2010. Available online: https:/ / rossier.usc.edu/kaplan-study-receives-grant-from-the-us-department-of-education/ (accessed on 12 October 2021).

5. Van Tassel-Baska, J.; Hubbard, G.F.; Robbins, J.I. Differentiation of Instruction for Gifted Learners: Collated Evaluative Studies of Teacher Classroom Practices. Roeper Rev. 2020, 42, 153-164. [CrossRef]

6. Johnsen, S.K.; Fearon-Drake, D.; Wisely, L.W. A Formative Evaluation of Differentiation Practices in Elementary Cluster Classrooms. Roeper Rev. 2020, 42, 206-218. [CrossRef]

7. Reis, S.M.; Renzulli, S.J.; Renzulli, J.S. Enrichment and Gifted Education Pedagogy to Develop Talents, Gifts, and Creative Productivity. Educ. Sci. 2021, 11, 615. [CrossRef]

8. Tomlinson, C.; Kaplan, S.N.; Renzulli, J.S.; Purcell, J.H.; Leppien, J.H.; Burns, D.E.; Strickland, C.A.; Imbeau, M.B. The Parallel Curriculum, 2nd ed.; Corwin Press: Thousand Oaks, CA, USA, 2009.

9. Joyce, B.R.; Weil, M.; Calhoun, E. Models of Teaching, 9th ed.; Pearson: Upper Saddle River, NJ, USA, 2015. 